\title{
Comparative analysis of US real-world dosing patterns and direct infusion-related costs for matched cohorts of rheumatoid arthritis patients treated with infliximab or intravenous golimumab
}

This article was published in the following Dove Press journal:

ClinicoEconomics and Outcomes Research

\author{
Lorie A Ellis' \\ Elisabetta Malangone- \\ Monaco ${ }^{2}$ \\ Helen Varker ${ }^{3}$ \\ Diana Stetsovsky ${ }^{3}$ \\ Maureen Kubacki \\ Raphael J DeHoratius ${ }^{1,4}$ \\ Shelly Kafka' \\ 'Real World Value and Evidence, \\ Janssen Scientific Affairs, LLC, \\ Horsham, PA, USA; ${ }^{2}$ Life Sciences, \\ IBM Watson Health, Armonk, NY \\ USA; ${ }^{3}$ Life Sciences, IBM Watson \\ Health, Cambridge, MA, USA; ${ }^{4}$ Janssen \\ Immunology, Medical Affairs, Sidney \\ Kimmel School of Medicine, Thomas \\ Jefferson University, Philadelphia, PA, \\ USA
}

Correspondence: Elisabetta

Malangone-Monaco

Life Sciences, IBM Watson Health, I

North Castle Drive, Armonk, NY 10504, USA

Tel + I 9147934094

Fax + I 9147934094

Emailemonaco@us.ibm.com
Purpose: The objectives of this study were to evaluate and compare treatment patterns and infusion-related health care resource expenditures for rheumatoid arthritis (RA) patients initiating golimumab for intravenous use (GLM-IV) and infliximab (IFX) therapy and to assess cost implications from the commercial perspective.

Methods: Adult RA patients with a new episode of GLM-IV or IFX treatment between January 1, 2014 and March 31, 2016 were identified from MarketScan databases and evaluated for maintenance infusion intervals and related costs of treatment. IFX and GLM-IV patients were matched 1:1 on index medication treatment duration, gender, payer type, prior biologic use, and post-index methotrexate use. Paid amounts for drugs and associated administration costs were applied to treatment group dosing patterns.

Results: Final matched treatment groups included 547 GLM-IV and 547 IFX patients (mean age = 55-56 years). Mean (SD) follow-up was 609 (161) days for GLM-IV and 613 (163) days for IFX. Treatment duration was 396 (240) days for GLM-IV and 397 (239) days for IFX. Overall, $80 \%$ of GLM-IV and $39 \%$ of IFX maintenance infusions were given approximately every 8 weeks; and $6 \%$ of GLM-IV and 53\% of IFX maintenance infusions occurred more frequently than every 8 weeks $(P<0.001)$. When weighting of the maintenance infusion interval was applied, the mean number of induction plus maintenance infusions during the first year of treatment was estimated at 7.03 for GLM-IV and 9.48 for IFX. From the commercial perspective, drug plus administration costs per infusion were $\$ 5,846$ for GLM-IV and $\$ 5,444$ for IFX with total annual cost of therapy for GLM-IV patients costing $\$ 10,507$ less than that for IFX patients in the first year and $\$ 6,774$ less than that for IFX patients in subsequent years.

Conclusion: Annual GLM-IV drug plus administration costs for commercial health plans were significantly less than IFX in RA patients due to differences in real-world dosing and administration.

Keywords: rheumatoid arthritis, infliximab, golimumab, dosing, treatment patterns

\section{Introduction}

Rheumatoid arthritis (RA) is the most common adult chronic inflammatory arthritis condition, affecting $\sim 0.5 \%$ to $1 \%$ of the world population, including an estimated 1.3-1.8 million Americans. ${ }^{1,2}$ This autoimmune disease appears to stem from genetic susceptibility and environmental triggers in which B-cell and T-cell activation, autoantibody production, tumor necrosis factor alpha (TNF- $\alpha$ ), and IL-6 play central roles. The characteristic joint synovium inflammation and degenerative articular changes 
are often accompanied by systemic complications of the underlying disease, such as those affecting cardiovascular, pulmonary, and gastrointestinal systems; cancers; and psychiatric diseases. ${ }^{1,3}$ Annual economic costs for RA in the USA were estimated at $\$ 8.4$ billion (2,005 dollars) in direct health care expenditures and $\$ 10.9$ billion in indirect costs resulting from the disease and comorbid conditions, along with psychosocial effects of the disease and impacts on health-related quality of life. ${ }^{4}$

Treatment guidelines focus on managing inflammation, preventing structural damage, controlling pain, and managing comorbid conditions with the goal of optimizing patients' participation in activities of daily living by using a treat-totarget strategy that adjusts therapy to meet treatment goals..$^{5-7}$ Early intervention with disease-modifying antirheumatic drugs (DMARDs) has become the backbone of the treatto-target approach, in which therapy is regularly reassessed based on progress toward relieving signs and symptoms and minimizing disease activity. ${ }^{3,8}$ Initial therapy typically involves conventional DMARDs, such as methotrexate, leflunomide, or sulfasalazine. For patients with moderate or high disease activity, the guidelines from the American College of Rheumatology recommend use of conventional DMARD combinations with or without a biologic targeted immune therapy or biologic therapy alone, such as abatacept, adalimumab, etanercept, golimumab, and infliximab (IFX). ${ }^{9}$ The most prevalent biologics used for RA are the TNF inhibitors (anti-TNF agents); however, US guidelines do not provide recommendations for prioritizing between agents of the same class, leaving this decision solely in the hands of individual providers. ${ }^{2,5,9}$

Golimumab (GLM) for intravenous use (GLM-IV) and IFX are currently the only anti-TNF agents approved in the USA for IV administration in treating patients with RA. Despite having similar mechanisms of action, there are significant differences in dosing and administration recommendations between GLM-IV and IFX. GLM is a fully human monoclonal antibody specific for human TNF- $\alpha$, approved for IV administration in July 2013 for moderate-to-severe active RA in combination with methotrexate. The $2 \mathrm{mg} / \mathrm{kg}$ dose is administered by IV infusion over 30 minutes at weeks 0 and 4 for induction and then as a maintenance regimen every 8 weeks. ${ }^{10,11}$ Under this dosing schedule, patients can receive seven GLM-IV infusions in their first year of therapy. IFX is a chimeric $\operatorname{IgG} 1 \kappa$ monoclonal antibody specific for human TNF- $\alpha$. The recommended $3 \mathrm{mg} / \mathrm{kg}$ dose is given by IV infusion over a minimum of 2 hours at weeks 0,2 , and 6 for induction, followed by a maintenance regimen every 8 weeks in combination with methotrexate. Patients with insufficient response may have the dose increased up to $10 \mathrm{mg} / \mathrm{kg}$ or may have the frequency increased up to every 4 weeks. ${ }^{12}$ Under this dosing schedule, patients can receive between 8 and 14 IFX infusions in their first year of therapy.

The differences in dosing and administration recommendations, as well as the subtle differences in protein structure between GLM-IV and IFX, can affect the use of health care resources and costs. However, no studies to date have directly compared the dosing and administration regimens and associated resource use and costs for these two IV anti-TNF RA medications in real-world populations. The comparison of these agents is complicated by noted differences in the populations treated with each agent since early studies have shown that a higher proportion of patients receiving GLM-IV tended to be older, with longer-standing active disease and had failed more prior biologic therapies compared with the population receiving IFX..$^{13,14}$ Therefore, studies in matched patient cohorts are important to ensure that confounding factors are controlled in any analysis.

The objectives of this study were to evaluate and compare the treatment patterns and infusion-related health care resource expenditures for matched RA patient cohorts initiating GLM-IV and IFX therapy identified in real-world health care claims data sets and to assess cost implications from the commercial perspective

\section{Methods}

\section{Study design}

This retrospective, observational cohort study used administrative health care claims data from a large geographically distributed US data source to examine the real-world dosing and administration patterns and direct infusion-related health care expenditures for matched patients during the first year after initiating RA treatment with either GLM-IV or IFX.

\section{Data source}

A de-identified US administrative health care claims database for years 2013-2016 was used for this study (MarketScan ${ }^{\circledR}$ Commercial Claims and Encounters Database and Medicare Supplemental and Coordination of Benefit Database [Truven Health Analytics, Ann Arbor, MI, USA]). The data consist of complete longitudinal records of inpatient services, outpatient services, and prescription drug claims for commercially insured and Medicare-eligible patients covered under a variety of health plans, including dates of service, places of service, and all payments. All database records are de-identified and fully compliant with 
US patient confidentiality requirements set forth in Sections 164.514 (a)-(b)1ii of the Health Insurance Portability and Accountability Act regarding the determination and documentation of statistically de-identified data; therefore, Institutional Review Board approval to conduct this study was not necessary.

The measurement of study variables was based on inpatient medical, outpatient medical, and outpatient pharmaceutical claims data using ICD, Ninth Revision, Clinical Modification (ICD-9-CM) codes, ICD, Tenth Revision (ICD-10) codes, Current Procedural Terminology ${ }^{\circledR}$ (CPT) codes, Healthcare Common Procedure Coding System (HCPCS) codes, and US National Drug Codes (NDCs), as appropriate.

\section{Subject selection}

Adult patients (at least 18 years of age on the index date) were selected if they had an ICD-CM diagnosis code for RA (ICD-9: 714.xx; ICD-10 diagnosis codes: M05, M06) in the 12 months before or within 30 days following the first medical claim for GLM-IV (HCPCS code J1604) or IFX (HCPCS code J1745) during the study identification period (January 1, 2014 and March 31, 2016). The study index date was defined as the first observed claim for GLM-IV or IFX during the study identification period. No evidence of prior index medication use in the 12 months prior to index was permitted. All patients had continuous medical and pharmacy benefit enrollment for at least 12 months before index (baseline period) and for at least 12 months following the index date (follow-up period). Patients were excluded if they had a diagnosis code for pregnancy observed in the data at any time.

Patient demographic, clinical, and post-index characteristics were assessed for the GLM-IV and IFX index cohorts to assess the need for matching. Demographic variables measured on the index date included age, sex, payer (Commercial or Medicare), health plan type, and geographic region of residence (Northeast, North Central, South, West). Clinical characteristics found in medical claims over the entire 12-month pre-index period included indices for RA severity and comorbidity burden. The claims-based index for RA severity (CIRAS) uses claims data for a medical records-based index of RA severity. ${ }^{15}$ The Deyo-Charlson Comorbidity Index (DCI) is an aggregate measure of comorbidity based on weighted values for select diagnoses, which was adjusted to eliminate RA from its computation since all patients will have that diagnosis. ${ }^{16}$ The number of unique diagnoses is based on counts of the unique diagnoses at the 3-digit ICD-9-CM and ICD-10 level, and the number of unique prescription drugs counts the total number of unique NDCs in outpatient prescription claims. ${ }^{17}$ The presence of specific comorbidities of interest included essential hypertension, disorders of lipid metabolism, respiratory symptoms, diabetes mellitus, depression, osteoporosis, interstitial lung disease, ischemic heart disease, psoriatic arthritis, and psoriasis. Pre-index usage of RA-indicated biologics and non-biologic DMARDs, including methotrexate, corticosteroids, hydroxychloroquine, leflunomide, sulfasalazine, and azathioprine, was summarized from prescription claims.

After assessment of the baseline and follow-up variables, patients in the GLM-IV cohort were matched 1:1 with IFX patients on the following variables: gender, payer type, prior biologic use, index medication treatment duration, and postindex methotrexate use.

\section{Outcomes}

Key outcome variables included dosing and administration, treatment patterns, and costs.

Dosing and administration outcomes consisted of the number of infusions, the number of vials per infusion of the index drug, and the infusion interval for induction and maintenance infusions of the index drug. The number of index drug infusions was calculated for outpatient medical claims of the study drug occurring at the physician's office, in a clinic, or other outpatient facility. Vials of study drug per infusion were computed by dividing the paid amount of the drug claim by the published wholesale acquisition cost (Analysource) for the applicable time period of the paid claim. Infusions were designated as either induction or maintenance according to the administration schedules in each drug's prescribing information, with the first two GLM-IV infusions and the first three IFX infusions identified as induction doses and all subsequent doses considered maintenance. ${ }^{12}$ The infusion interval between administrations was calculated as the number of days between claims for a study drug.

Treatment pattern outcomes included index medication persistence (treatment duration and proportion of patients with an index discontinuation), administration billing time and procedures, and concomitant use of methotrexate or corticosteroids during index medication use in the followup period. Treatment duration was calculated as the number of days from the index date until the date of the last drug administration claim in the dataset plus a clinical benefit period equal to 56 days. Discontinuation was assessed as the proportion of patients who discontinued index medication over the follow-up period and as the total index treatment 
duration. Discontinuation was determined by a switch to a non-index biologic or the absence of a claim for the study index medication for at least 168 days (three times the clinical benefit of 56 days) after the last observed claim. Concomitant usage of methotrexate and/or corticosteroids was based on the respective days of supply in outpatient prescription claims on or after the index date through the duration of index drug therapy.

Drug and infusion costs were computed from total paid amounts on adjudicated claims, including health plan payments, patient copayments, deductibles, and coinsurance. Inflation was adjusted to 2,017 US dollars using the Medical Care component of the US Bureau of Labor Statistics Consumer Price Index. ${ }^{18}$ Infusion-related costs were obtained for claims on the same day as the drug claim with the following CPT codes: first hour 96365, 96413; additional hour 96366, 96415; IV push 96372, 96374, 96375; additional sequential infusion 96367. Average drug and administration costs per IFX infusion or GLM-IV infusion were derived from all observed GLM-IV and IFX infusions provided there was a valid cost value. Claims with $\$ 0$ cost were excluded. The drug and administration costs of the first year following GLM-IV or IFX initiation were computed in two ways by multiplying the average drug plus administration cost per infusion by a) the expected number of infusions based on the approved dosage and administration in the prescribing information, and b) the weighted number of infusions in a given year from this study's results. The weighted number of infusions per year was computed from the proportion of maintenance infusion intervals occurring plus the addition of the indicated number of induction intervals.

\section{Analysis}

Bivariate analyses of all dependent and independent variables were summarized descriptively, with categorical variables presented as the count and percentage of patients, and continuous variables providing the number of observations, the mean, SD, and median. Statistical tests of significance for observed differences between treatment groups were conducted using chi-squared tests for categorical variables and $t$-tests for continuous variables. The threshold of statistical significance for all analyses was set a priori at 0.05. All analyses were conducted using SAS software, version 9.4 (SAS Institute Inc, Cary, NC).

\section{Results}

\section{Population characteristics}

The initial unmatched study samples consisted of 647 GLMIV and 881 IFX patients (Figure 1, Table). After matching
1:1 for gender, payer type, prior biologic use, index medication treatment duration, and post-index methotrexate use, the final study sample consisted of 547 GLM-IV and 547 IFX patients adequately matched for baseline demographics and clinical characteristics and index medication treatment duration in the follow-up period (Tables $1-4)$. The matched populations were predominantly female ( $82 \%)$ with mean age 55-56 years (Table 3 ). Indices of RA severity and comorbidity burden were not statistically different between matched treatment groups (Table 4). Common comorbidities included hypertension, disorders of lipid metabolism, respiratory symptoms, and diabetes (Table 4). Prior to initiating GLMIV or IFX treatment, over half of the patients had treatment with methotrexate $55.0 \%$ of GLM-IV and $60.0 \%$ of IFX patients) and $38.2 \%$ of all patients had no prior biologic use. Pre-index corticosteroid use was found in $47.7 \%$ of GLM-IV and $44.6 \%$ of IFX patients (Table 4 ).

\section{Post-index treatment patterns}

The mean (SD) post-index follow-up was 609 (161) days for GLM-IV patients and 613 (163) days for IFX patients (Table 3), during which the mean treatment duration was 396 (240) days for GLM-IV and 397 (239) days for IFX therapy (Table 5). Discontinuation occurred for $53.7 \%$ of patients in both cohorts at a mean of 241 (165) days for GLM-IV and 244 (171) days for IFX patients.

Post-index concomitant methotrexate use was observed in $51.7 \%$ of patients in both GLM-IV and IFX treatment cohorts for approximately one-third of total treatment days. Post-index concomitant corticosteroid use was observed in $38 \%$ and $49 \%$ of GLM-IV- and IFX-treated patients, respectively, although use was limited, occurring in only $2.2 \%$ and $3.9 \%$ of GLM and IFX treatment days, respectively (Table 5).

\section{Dosing and administration outcomes}

A total of 3,961 GLM-IV and 4,716 IFX infusions were administered during the study period. GLM-IV patients received significantly fewer infusions per patient during follow-up compared with IFX patients. The mean (SD) number of induction plus maintenance infusions per patient observed during follow-up was 7.2 (4.3) for GLM-IV vs 8.6 (5.6) for IFX ( $P=0.018$, Table 5). Likewise, on average, GLM-IV patients in this study required fewer vials per infusion (4.1) than did IFX patients (4.7; Table 5). All GLM-IV and IFX infusions were associated with a claim for at least 1 hour of billed infusion time; however, fewer than $1 \%$ of GLM-IV infusions vs $96 \%$ of IFX infusions had claims for more than 1 hour of billed infusion time. 


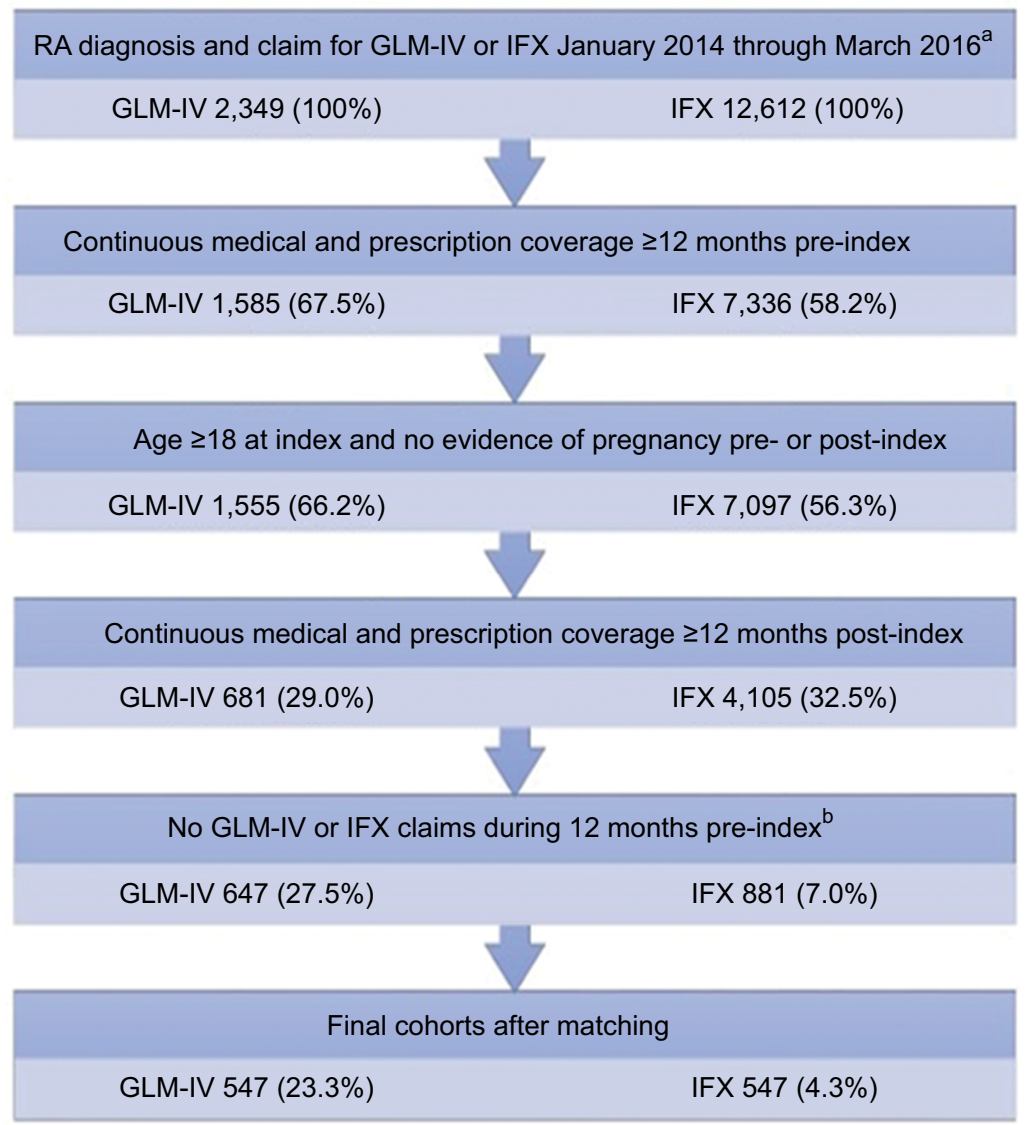

Figure I Subject selection.

Note: andex date is the first GLM-IV or IFX claim after January I, 20I4. 'Patients may not have had their index medication within I2 months pre-index; however, they may have received the non-index drug during the pre-index period. In addition, patients could have no claims for a second non-study biologic on the index date.

Abbreviations: GLM-IV, golimumab intravenous; IFX, infliximab; RA, rheumatoid arthritis.

Table I Demographic characteristics of patients prior to matching

\begin{tabular}{|c|c|c|c|c|c|}
\hline \multirow[b]{2}{*}{ Age, years (mean, SD) } & \multicolumn{2}{|l|}{$\begin{array}{l}\text { GLM-IV } \\
N=647\end{array}$} & \multicolumn{2}{|l|}{$\begin{array}{l}\text { IFX } \\
N=88 \text { I }\end{array}$} & \multirow{2}{*}{\begin{tabular}{|l|}
$P$-value \\
0.014 \\
\end{tabular}} \\
\hline & 57.3 & 12.8 & 55.7 & 12.3 & \\
\hline Age group (N, \%) & & & & & 0.269 \\
\hline $18-34$ & 24 & $3.7 \%$ & 41 & $4.7 \%$ & \\
\hline $35-44$ & 72 & $11.1 \%$ & 113 & $12.8 \%$ & \\
\hline $45-54$ & 174 & $26.9 \%$ & 221 & $25.1 \%$ & \\
\hline $55-64$ & 216 & $33.4 \%$ & 319 & $36.2 \%$ & \\
\hline $65+$ & 161 & $24.9 \%$ & 187 & $21.2 \%$ & \\
\hline Sex $(\%, N)$ & & & & & 0.017 \\
\hline Male & 116 & $17.9 \%$ & 202 & $22.9 \%$ & \\
\hline Female & 531 & $82.1 \%$ & 679 & $77.1 \%$ & \\
\hline Payer (N, \%) & & & & & 0.167 \\
\hline Commercial & 475 & $73.4 \%$ & 674 & $76.5 \%$ & \\
\hline Medicare & 172 & $26.6 \%$ & 207 & $23.5 \%$ & \\
\hline Length of follow-up, days (mean, SD) & 614 & 161 & 627 & 163 & 0.122 \\
\hline Total all-cause pre-index health care costs, $\$$ (mean, SD) & $\$ 44,255$ & $\$ 76,35 \mathrm{I}$ & $\$ 34,027$ & $\$ 37,370$ & $<0.001$ \\
\hline
\end{tabular}

Abbreviations: GLM-IV, golimumab intravenous; IFX, infliximab. 
Table 2 Clinical characteristics of patients prior to matching

\begin{tabular}{|c|c|c|c|c|c|}
\hline \multirow{2}{*}{ RA and comorbidity indices (mean, SD) } & \multicolumn{2}{|c|}{$\begin{array}{l}\text { GLM-IV } \\
N=647\end{array}$} & \multicolumn{2}{|c|}{$\begin{array}{l}\text { IFX } \\
\mathbf{N}=\mathbf{8 8} \text { I }\end{array}$} & \multirow[t]{2}{*}{$P$-value } \\
\hline & & & & & \\
\hline CIRAS & 5.81 & 1.71 & 5.95 & 1.89 & 0.118 \\
\hline $\mathbf{D C l}^{\mathbf{a}}$ & 0.76 & 1.18 & 0.71 & 1.23 & 0.398 \\
\hline Number of unique diagnoses ${ }^{b}$ & 21 & 11.18 & 20 & 11.33 & 0.406 \\
\hline Number of unique prescription drugs & 18 & 10.50 & 18 & 10.62 & 0.740 \\
\hline \multicolumn{6}{|l|}{ Specific comorbid conditions (N, \%) } \\
\hline Essential hypertension & 296 & $45.7 \%$ & 373 & $42.3 \%$ & 0.184 \\
\hline Disorders of lipoid metabolism & 221 & $34.2 \%$ & 285 & $32.3 \%$ & 0.458 \\
\hline Respiratory symptoms & 204 & $31.5 \%$ & 254 & $28.8 \%$ & 0.255 \\
\hline Diabetes & 120 & $18.5 \%$ & 141 & $16.0 \%$ & 0.192 \\
\hline Depression & 74 & $11.4 \%$ & 107 & $12.1 \%$ & 0.672 \\
\hline Osteoporosis & 74 & $1 \mathrm{I} .4 \%$ & 96 & $10.9 \%$ & 0.740 \\
\hline Interstitial lung disease & 55 & $8.5 \%$ & 85 & $9.6 \%$ & 0.442 \\
\hline Ischemic heart disease & 60 & $9.3 \%$ & 83 & $9.4 \%$ & 0.922 \\
\hline Psoriatic arthritis & 41 & $6.3 \%$ & 51 & $5.8 \%$ & 0.656 \\
\hline Psoriasis & 36 & $5.6 \%$ & 38 & $4.3 \%$ & 0.260 \\
\hline \multicolumn{6}{|l|}{ Pre-index non-biologic DMARD use (N, \%) } \\
\hline Methotrexate & 340 & $52.6 \%$ & 536 & $60.8 \%$ & 0.001 \\
\hline Corticosteroids & 316 & $48.8 \%$ & 362 & $41.1 \%$ & 0.003 \\
\hline \multicolumn{6}{|l|}{ Pre-index biologic use (N, \%) } \\
\hline No biologics & 210 & $32.5 \%$ & 513 & $58.2 \%$ & $<0.001$ \\
\hline Infliximab & 137 & $21.2 \%$ & 0 & $0.0 \%$ & $<0.001$ \\
\hline Abatacept & 104 & $16.1 \%$ & 62 & $7.0 \%$ & $<0.001$ \\
\hline Tocilizumab & 83 & $12.8 \%$ & 43 & $4.9 \%$ & $<0.001$ \\
\hline Adalimumab & 64 & $9.9 \%$ & 163 & $18.5 \%$ & $<0.001$ \\
\hline Etanercept & 57 & $8.8 \%$ & 139 & $15.8 \%$ & $<0.001$ \\
\hline Tofacitinib & 31 & $4.8 \%$ & 23 & $2.6 \%$ & 0.023 \\
\hline Certolizumab pegot & 40 & $6.2 \%$ & 32 & $3.6 \%$ & 0.020 \\
\hline Golimumab subcutaneous & 22 & $3.4 \%$ & 12 & $1.4 \%$ & 0.008 \\
\hline Rituximab & 18 & $2.8 \%$ & 16 & $1.8 \%$ & 0.206 \\
\hline
\end{tabular}

Note: ${ }^{a}$ Calculations to determine $\mathrm{DCl}$ excludes rheumatologic disease. ${ }^{b} \mathrm{Number}$ of unique diagnoses was the number of unique three-digit ICD-9-CM codes found pre-index. Abbreviations: CIRAS, claims-based index for RA severity; DCI, Deyo-Charlson Comorbidity Index; DMARD, disease-modifying antirheumatic drug; GLM-IV, golimumab intravenous; ICD-9-CM, ICD Ninth Revision, Clinical Modification; IFX, infliximab; RA, rheumatoid arthritis.

Table 3 Demographic characteristics of matched patients

\begin{tabular}{|c|c|c|c|c|c|}
\hline \multirow[b]{2}{*}{ Age, years (mean, SD) } & \multicolumn{2}{|l|}{$\begin{array}{l}\text { GLM-IV } \\
N=547\end{array}$} & \multicolumn{2}{|l|}{$\begin{array}{l}\text { IFX } \\
N=547\end{array}$} & \multirow{2}{*}{$\begin{array}{l}\text { P-value } \\
0.119 \\
\end{array}$} \\
\hline & 56.3 & 12.3 & 55.1 & 12.4 & \\
\hline Age group (N, \%) & & & & & 0.601 \\
\hline $18-34$ & 22 & $4.0 \%$ & 29 & $5.3 \%$ & \\
\hline $35-44$ & 60 & $11.0 \%$ & 68 & $12.4 \%$ & \\
\hline $45-54$ & 160 & $29.3 \%$ & 143 & $26.1 \%$ & \\
\hline $55-64$ & 196 & $35.8 \%$ & 204 & $37.3 \%$ & \\
\hline $65+$ & 109 & $19.9 \%$ & 103 & $18.8 \%$ & \\
\hline $\operatorname{Sex}(\%, \mathbf{N})$ & & & & & 1.000 \\
\hline Male & 97 & $17.7 \%$ & 97 & $17.7 \%$ & \\
\hline Female & 450 & $82.3 \%$ & 450 & $82.3 \%$ & \\
\hline Payer (N, \%) & & & & & 1.000 \\
\hline Commercial & 431 & $78.8 \%$ & 431 & $78.8 \%$ & \\
\hline Medicare & 116 & $21.2 \%$ & 116 & $21.2 \%$ & \\
\hline Length of follow-up, days (mean, SD) & 609 & 161 & 613 & 163 & 0.688 \\
\hline Total all-cause pre-index health care costs, $\$$ (mean, SD) & $\$ 43,118$ & $\$ 80,018$ & $\$ 38,396$ & $\$ 38,945$ & 0.215 \\
\hline
\end{tabular}

Abbreviations: GLM-IV, golimumab intravenous; IFX, infliximab. 
Table 4 Clinical characteristics of matched patients

\begin{tabular}{|c|c|c|c|c|c|}
\hline \multirow{2}{*}{ RA and comorbidity indices (mean, SD) } & \multicolumn{2}{|c|}{$\begin{array}{l}\text { GLM-IV } \\
\mathrm{N}=547 \\
\end{array}$} & \multicolumn{2}{|c|}{\begin{tabular}{|l|} 
IFX \\
$N=547$ \\
\end{tabular}} & \multirow[t]{2}{*}{$P$-value } \\
\hline & & & & & \\
\hline CIRAS & 5.93 & 1.69 & 6.06 & 1.78 & 0.213 \\
\hline $\mathbf{D C l}^{\mathbf{a}}$ & 0.73 & 1.15 & 0.71 & 1.29 & 0.824 \\
\hline Number of unique diagnoses ${ }^{b}$ & 20 & 10.74 & 21 & 11.30 & 0.337 \\
\hline Number of unique prescription drugs & 18 & 10.47 & 20 & 10.41 & 0.017 \\
\hline \multicolumn{6}{|l|}{ Specific comorbid conditions (N, \%) } \\
\hline Essential hypertension & 240 & $43.9 \%$ & 236 & $43.1 \%$ & 0.807 \\
\hline Disorders of lipoid metabolism & 176 & $32.2 \%$ & 178 & $32.5 \%$ & 0.897 \\
\hline Respiratory symptoms & 171 & $31.3 \%$ & 161 & $29.4 \%$ & $0.5 \mathrm{II}$ \\
\hline Diabetes & 100 & $18.3 \%$ & 84 & $15.4 \%$ & 0.196 \\
\hline Depression & 62 & $11.3 \%$ & 69 & $12.6 \%$ & 0.514 \\
\hline Osteoporosis & 60 & $11.0 \%$ & 53 & $9.7 \%$ & 0.487 \\
\hline Interstitial lung disease & 49 & $9.0 \%$ & 45 & $8.2 \%$ & 0.666 \\
\hline Ischemic heart disease & 47 & $8.6 \%$ & 46 & $8.4 \%$ & 0.914 \\
\hline Psoriatic arthritis & 34 & $6.2 \%$ & 35 & $6.4 \%$ & 0.901 \\
\hline Psoriasis & 27 & $4.9 \%$ & 27 & $4.9 \%$ & 1.000 \\
\hline \multicolumn{6}{|l|}{ Pre-index non-biologic DMARD use (N, \%) } \\
\hline Methotrexate & 301 & $55.0 \%$ & 328 & $60.0 \%$ & 0.099 \\
\hline Corticosteroids & 261 & $47.7 \%$ & 244 & $44.6 \%$ & 0.303 \\
\hline \multicolumn{6}{|l|}{ Pre-index biologic use (N, \%) } \\
\hline No biologics & 209 & $38.2 \%$ & 209 & $38.2 \%$ & 1.000 \\
\hline Infliximab & 106 & $19.4 \%$ & 0 & $0.0 \%$ & $<0.001$ \\
\hline Abatacept & 74 & $13.5 \%$ & 55 & $10.1 \%$ & 0.024 \\
\hline Tocilizumab & 63 & $11.5 \%$ & 37 & $6.8 \%$ & $<0.001$ \\
\hline Adalimumab & 57 & $10.4 \%$ & 143 & $26.1 \%$ & $<0.001$ \\
\hline Etanercept & 44 & $8.0 \%$ & 134 & $24.5 \%$ & $<0.001$ \\
\hline Tofacitinib & 29 & $5.3 \%$ & 22 & $4.0 \%$ & 0.315 \\
\hline Certolizumab pegot & 26 & $4.8 \%$ & 30 & $5.5 \%$ & 0.583 \\
\hline Golimumab subcutaneous & 15 & $2.7 \%$ & 11 & $2.0 \%$ & 0.427 \\
\hline Rituximab & 10 & $1.8 \%$ & 14 & $2.6 \%$ & 0.409 \\
\hline
\end{tabular}

Note: a Calculations to determine $\mathrm{DCl}$ excludes rheumatologic disease. ${ }^{b} \mathrm{Number}$ of unique diagnoses was the number of unique three-digit ICD-9-CM codes found pre-index. Abbreviations: CIRAS, claims-based index for RA severity; DCI, Deyo-Charlson Comorbidity Index; DMARD, disease-modifying antirheumatic drug; GLM-IV, golimumab intravenous; ICD-9-CM, ICD Ninth Revision, Clinical Modification; IFX, infliximab; RA, rheumatoid arthritis.

The proportion of maintenance infusions administered approximately every 8 weeks ( $>7$ weeks and $\leq 9$ weeks) was $80.2 \%$ for GLM-IV vs $38.6 \%$ for IFX ( $P<0.001$, Figure 2$)$. The proportion of infusions that occurred more frequently than every 8 weeks was $5.9 \%$ for GLM-IV infusions compared to $52.8 \%$ for IFX infusions $(P<0.001$, Table 5$)$. The proportion of infusion intervals exceeding 9 weeks was $13.9 \%$ for GLM-IV and $8.6 \%$ for IFX with the average infusion interval in this category being 12 weeks.

When weighting of the maintenance infusion interval was applied, the annual number of maintenance infusions was estimated as 5.05 for GLM-IV and 6.48 for IFX infusions and the number of total induction plus maintenance infusions per the first year of therapy was estimated at 7.03 for GLM-IV and 9.48 for IFX.

Total mean drug cost per infusion for commercially insured patients receiving GLM-IV therapy was $\$ 5,622$
$(\$ 3,641)$ and $\$ 5,083(\$ 4,339)$ for IFX (Table 6). Mean administration cost per infusion for commercially insured GLM-IV infusions was \$224 (\$151) and \$360 (\$281) for IFX infusions.

\section{Estimation of annual cost of therapy from the commercial perspective}

The annual drug plus administration costs for the first year of GLM-IV therapy was estimated based on the recommended dosing in the GLM-IV and IFX prescribing information. Based on a total of seven infusions in the first year (two induction infusions occurring at weeks 0 and 4 and five maintenance infusions occurring at an infusion interval of every 8 weeks) and the commercial cost per infusion (Table 6), the expected GLM-IV drug plus administration cost in the first year was estimated at $\$ 40,922$ (Figure 3). Based on a total of eight infusions for IFX recommended in the prescribing 
Table 5 Treatment patterns and infusion patterns

\begin{tabular}{|c|c|c|c|c|c|}
\hline \multirow[b]{2}{*}{ Days from last pre-index biologic dose to index date (mean, SD) } & \multicolumn{2}{|c|}{$\begin{array}{l}\text { GLM-IV } \\
N=547\end{array}$} & \multicolumn{2}{|c|}{$\begin{array}{l}\text { IFX } \\
N=547\end{array}$} & \multirow{2}{*}{\begin{tabular}{|l|} 
P-value \\
0.424 \\
\end{tabular}} \\
\hline & 68.6 & 42.3 & 70.6 & 41.3 & \\
\hline Duration of index therapy, days (mean, SD) & 396 & 240 & 397 & 239 & 0.928 \\
\hline Patients who discontinued or switched (N, \%) & 294 & $53.7 \%$ & 294 & $53.7 \%$ & 1.000 \\
\hline Discontinued index medication (N, \%) & 119 & $21.8 \%$ & 162 & $29.6 \%$ & 0.003 \\
\hline Switched to a different biologic (N, \%) & 175 & $32.0 \%$ & 132 & $24.1 \%$ & 0.004 \\
\hline Days to discontinuation or switch (mean, SD) & 241 & 165 & 244 & 171 & 0.799 \\
\hline Concomitant methotrexate use $(\mathrm{N}, \%)$ & 283 & $51.7 \%$ & 283 & $51.7 \%$ & 1.000 \\
\hline Days of concomitant methotrexate (mean, SD) & $34.7 \%$ & $39.4 \%$ & $35.0 \%$ & $40.4 \%$ & 0.892 \\
\hline Concomitant corticosteroid use (N, \%) & 210 & $38.4 \%$ & 268 & $49.0 \%$ & $<0.001$ \\
\hline Days of concomitant corticosteroids (mean, SD) & $2.2 \%$ & $4.3 \%$ & $3.9 \%$ & $6.6 \%$ & $<0.001$ \\
\hline Total number of index drug infusions & 3,961 & & 4,716 & & \\
\hline Number of infusions per patient (mean, SD) & 7.2 & 4.3 & 8.6 & 5.6 & 0.018 \\
\hline I (N, \%) & 30 & $5.5 \%$ & 42 & $7.7 \%$ & \\
\hline $2(N, \%)$ & 57 & $10.4 \%$ & 45 & $8.2 \%$ & \\
\hline $3(\mathbf{N}, \%)$ & 54 & $9.9 \%$ & 30 & $5.5 \%$ & \\
\hline $4(N, \%)$ & 50 & $9.1 \%$ & 44 & $8.0 \%$ & \\
\hline $5+(N, \%)$ & 356 & $65.1 \%$ & 386 & $70.6 \%$ & \\
\hline Vials per infusion $^{a}$ (mean, SD) & 4.1 & 2.6 & 4.7 & 4.0 & $<0.001$ \\
\hline Induction intervals ${ }^{\mathrm{b}, \mathrm{c}}(\mathrm{N}, \%)$ & & & & & $<0.001$ \\
\hline$\leq 2$ weeks & 2 & $0.4 \%$ & 296 & $30.7 \%$ & \\
\hline$>2$ weeks $\leq 3$ weeks & 4 & $0.8 \%$ & 111 & $11.5 \%$ & \\
\hline$>3$ weeks $\leq 4$ weeks & 270 & $52.2 \%$ & 259 & $26.8 \%$ & \\
\hline$>4$ weeks $\leq 5$ weeks & 127 & $24.6 \%$ & 104 & $10.8 \%$ & \\
\hline$>5$ weeks $\leq 7$ weeks & 30 & $5.8 \%$ & 94 & $9.7 \%$ & \\
\hline$>7$ weeks $\leq 9$ weeks & 55 & $10.6 \%$ & 58 & $6.0 \%$ & \\
\hline$>9$ weeks & 29 & $5.6 \%$ & 43 & $4.5 \%$ & \\
\hline Maintenance intervals $\mathbf{s}^{\mathrm{b}, \mathrm{c}}(\mathrm{N}, \%)$ & & & & & $<0.001$ \\
\hline$\leq 4$ weeks & 55 & $1.9 \%$ & 330 & $10.3 \%$ & \\
\hline$>4$ weeks $\leq 5$ weeks & 16 & $0.6 \%$ & 228 & $7.1 \%$ & \\
\hline$>5$ weeks $\leq 7$ weeks & 100 & $3.5 \%$ & $\mathrm{I}, \mathrm{I} 35$ & $35.4 \%$ & \\
\hline$>7$ weeks $\leq 9$ weeks & 2,322 & $80.2 \%$ & 1,237 & $38.6 \%$ & \\
\hline$>9$ weeks $^{\mathrm{d}}$ & 404 & $13.9 \%$ & 274 & $8.6 \%$ & \\
\hline Interval durations, all intervals, days (mean, SD) & 54.1 & 13.9 & 44.3 & 32.4 & $<0.001$ \\
\hline Maintenance interval durations, days (mean, SD) & 59.6 & 14.8 & \begin{tabular}{|l|}
49.4 \\
\end{tabular} & 17.0 & $<0.001$ \\
\hline
\end{tabular}

Note: ${ }^{2}$ Vials per infusions were computed by dividing the amount paid by the wholesale acquisition cost. ${ }^{\circ}$ Count represents infusion intervals, not the number of infusions. For example, a patient with three infusions will have two infusion intervals. 'GLM-IV maintenance starts with the third dose, so dose interval two-to-three is the first GLM-IV maintenance interval. IFX maintenance starts with the fourth dose, so dose interval three-to-four is the first IFX maintenance interval. ${ }^{\mathrm{W}} \mathrm{W}$ hen maintenance infusion intervals exceeded 9 weeks, the average infusion interval was $\sim 12$ weeks for both IFX and GLM-IV cohorts.

Abbreviations: GLM-IV, golimumab intravenous; IFX, infliximab.

information (three induction infusions occurring at weeks 0 , 2 , and 6 and five maintenance infusions occurring at an infusion interval of every 8 weeks), and the commercial cost per infusion (Table 6), the expected IFX drug plus administration cost in the first year was estimated at \$43,552 (Figure 3).

When real-world dosing and administration data, weighted maintenance infusion intervals, and commercial costs were used, the first year of GLM-IV therapy (7.03 infusions/year) was estimated at $\$ 41,104$ while IFX therapy (9.48 infusions/year) was estimated at $\$ 51,611$ in the first year of therapy (Figure 3).

\section{Discussion}

This study, conducted on a large database population of US self-insured RA patients from diverse practice settings across the USA, found significant differences in treatment patterns between GLM-IV and IFX-treated patients; notably a significantly greater proportion of GLM-IV maintenance infusions were provided every 8 weeks with reduction of billed administration time that resulted in lower annual treatment cost per patient for commercial insurers. Taken together, these findings suggest that GLM-IV provides a more efficient treatment option for infused anti-TNF therapy. 


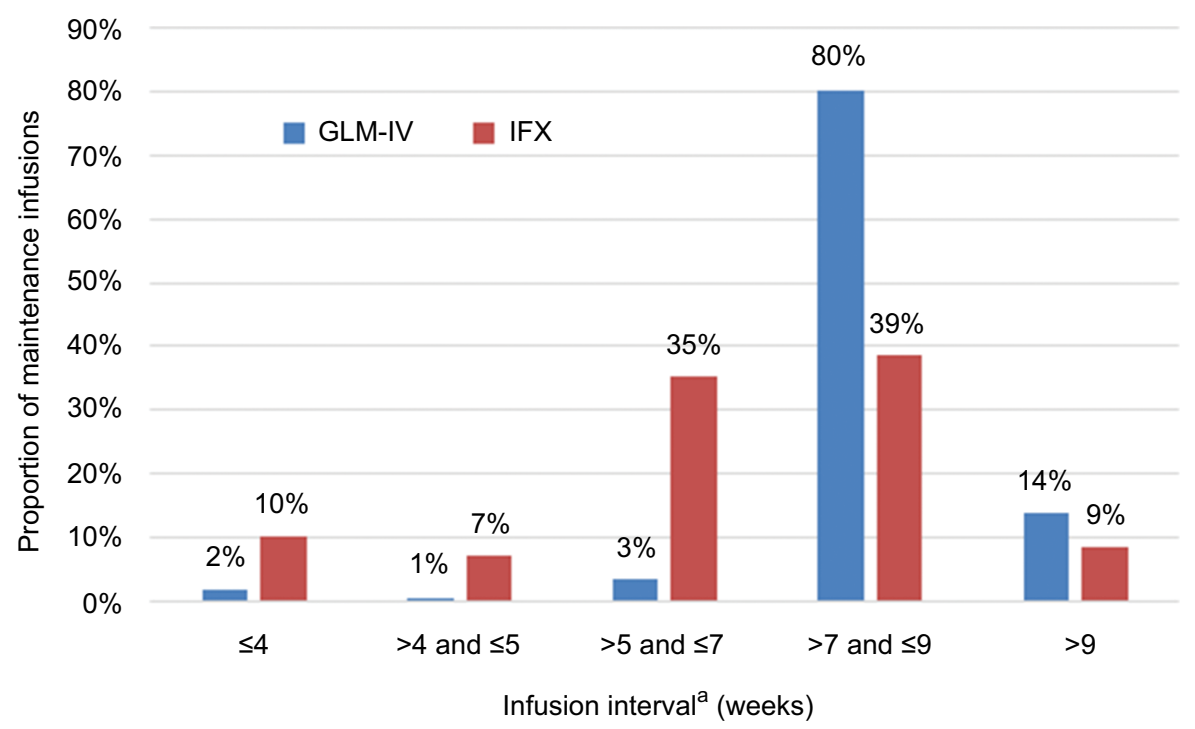

Figure 2 Distribution of maintenance infusions.

Notes: ${ }^{2}$ All differences between cohorts for the proportions of maintenance infusions are significant at $P<0.00 \mathrm{I}$. When maintenance infusion intervals exceeded 9 weeks, the average infusion interval was $\sim 12$ weeks for both IFX and GLM-IV cohorts.

Abbreviations: GLM-IV, golimumab intravenous; IFX, infliximab.

Table 6 Drug and infusion expenditures

\begin{tabular}{|c|c|c|c|c|}
\hline \multirow{2}{*}{ Drug costs per infusion ${ }^{a}$} & \multicolumn{2}{|c|}{$\begin{array}{l}\text { GLM-IV } \\
N=547\end{array}$} & \multicolumn{2}{|l|}{$\begin{array}{l}\text { IFX } \\
N=547\end{array}$} \\
\hline & & & & \\
\hline Commercial (N) & 3,090 & & 3,700 & \\
\hline Paid amount, \$ (mean, SD) & $\$ 5,622$ & $\$ 3,64 I$ & $\$ 5,083$ & $\$ 4,339$ \\
\hline \multicolumn{5}{|l|}{ Infusion costs per infusion ${ }^{a}$} \\
\hline All infusions with non-drug costs $(\mathrm{N})$ & 3,746 & & 4,487 & \\
\hline \multicolumn{5}{|l|}{ Commercial } \\
\hline Infusions with non-drug costs (N) & 2,964 & & 3,568 & \\
\hline Paid amount, \$ (mean, SD) & $\$ 224$ & $\$ 151$ & $\$ 360$ & $\$ 281$ \\
\hline
\end{tabular}

Note: ${ }^{\mathrm{E} E x c l u d e s}$ claims with zero dollar costs.

Abbreviations: GLM-IV, golimumab intravenous; IFX, infliximab.

Consideration of efficiency in the delivery of health care is growing in importance. The Institute of Medicine (IOM) has defined high quality of care as consisting of six important domains: safe, effective, timely, efficient, equitable, and patient-centered. ${ }^{19,20}$ Phase III studies of IFX and GLM-IV have demonstrated the safety and effectiveness, two of the six domains of high-quality health care, of both agents in patients with RA. Head-to-head studies of these agents have not been conducted to differentiate the clinical or safety profiles of these agents in RA patients, although differences in the protein structures of these agents could translate into differences in tolerability among patients treated with fully human vs chimeric murine/human proteins. To address this possibility, a real-world pragmatic trial is underway to assess whether the higher occurrence of infusion reactions for IFX than for GLM noted in Phase III trials is observed in the real-world setting. ${ }^{21}$

The findings from the present study, however, suggest that under the IOM framework, GLM-IV may achieve higher quality than IFX through impacting domains of timeliness and efficiency. Timeliness, as defined by Agency for Health care Research and Quality (AHRQ), is care that reduces wait times and harmful delays for both those who receive and those who give care. ${ }^{20}$ In this study, GLM-IV reduced billed infusion time for RA patients significantly compared with IFX. Logically, this reduction in billed administration time should be derived from reduced time in the clinic for patients, and possibly from fewer demands on infusion monitoring by staff. A recent time and motion study showed that nearly three GLM-IV patients could be treated in the same time 


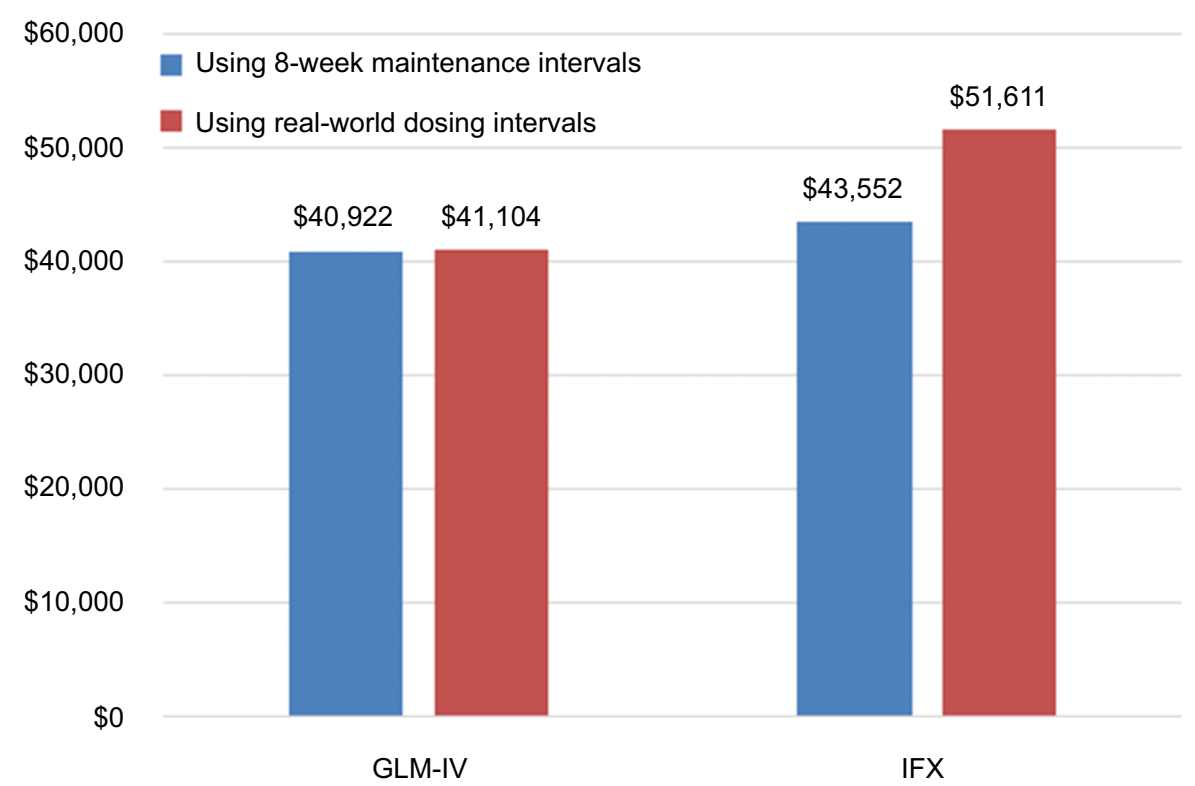

Figure 3 First-year costs of GLM-IV and IFX therapy comparing recommended dosing intervals and real-world dosing intervals in commercially insured patients. Abbreviations: GLM-IV, golimumab intravenous; IFX, infliximab.

required for one IFX infusion and that both patients and staff were more satisfied with the shorter in-clinic time associated with GLM-IV. ${ }^{22}$ Efficiency is defined by AHRQ as care that avoids waste, including waste of equipment, supplies, ideas, and energy. Under this construct, GLM-IV was associated with the expected number of infusions per year and fewer vials per infusion than IFX while nearly half of IFX infusions occurred more frequently than every 8 weeks. Taken together, these differences were estimated to equate to nearly $\$ 10,500$ per patient per year reduction in commercial payer costs.

The differences in real-world infusion patterns also impact other domains of health care quality, including providing patient-centered care. Fewer number of infusions and shorter infusion times may be important for patients who prefer an infusion but have greater life demands related to work or family. In this study, patients treated with GLM-IV required fewer infusion visits with each visit requiring less time as shown by billing records than that observed for IFX patients. Likewise, a more predictable, shorter infusion may translate into a greater patient capacity for physician offices, which are known to be the least costly sites of care for biologic infusion. ${ }^{14}$

Finally, this study demonstrated that efficiency and predictable dosing of GLM-IV could translate into cost savings, at least by the commercial payer over IFX. We were unable to assess whether treatment patterns of GLM-IV differed from those of biosimilar IFX because it was not present in the dataset during the time of this study. However, given the assumption that biosimilar IFX would likely demonstrate similar dosing and administration patterns to originator IFX, we were able to confirm that GLM-IV treatment patterns observed in this study would be cost saving over biosimilar IFX under commercial reimbursement scenarios. Further real-world studies will be needed to confirm these findings and further investigate how infused anti-TNF agents perform on various domains of health care quality and cost.

\section{Limitations}

Use of administrative health care claims, which were intended to support reimbursement, may impose limits on the data available for analyzing therapies and their outcomes. Misclassifications or errors affecting covariates and study outcomes resulting from data coding limitations, data entry error, and missing or inaccurate codes are possible when relying on administrative claims. Medication dosing and treatment patterns were based on data from medical and prescription claims in the absence of patient charts or physician attestations. It was, therefore, not possible to ascertain reasons for deviations from recommended dosing or confirm how patients actually took or reacted to their medications. Patients' medical and prescription history was limited to health care claims during the reporting years in this study, such that patients' other comorbidities, pharmacotherapy, or sociodemographic factors affecting the outcomes were unavailable. In addition, disease severity is not directly reported in claims data and must be inferred from claims-based scores, such as CIRAS and DCI along with prior use of biologics and post-index use of methotrexate. This analysis focused 
on RA patient populations found in MarketScan commercial and Medicare databases that are representative of US payers and reimbursed paid costs in the time frame studied. Findings should not be interpreted outside of RA-labeled indications and may not be generalizable to other US or international patient populations or reflective of current treatment cost dynamics.

\section{Conclusion}

Patients treated with GLM-IV therapy had more consistent dosing patterns than IFX-treated patients; this resulted in significantly lower drug plus administration costs for commercially insured RA patients than IFX in the first year of care. These findings have important implications for population health decision makers in understanding health care quality, variations in health care utilization, or cost-saving measures.

\section{Acknowledgments}

Editorial/medical writing support for this manuscript was provided by Jay Margolis, PharmD (IBM Watson Health).

\section{Disclosure}

Lorie A Ellis, Maureen Kubacki, and Shelly Kafka are employees of Janssen Scientific Affairs. Raphael J DeHoratius was an employee at Janssen Scientific Affairs at the time this work was conducted, however, has since retired. Elisabetta Malangone-Monaco, Helen Varker, and Diana Stetsovsky are employees of IBM Watson Health, which received compensation from Janssen Scientific Affairs for the overall conduct of the study and preparation of the manuscript. This study was sponsored by Janssen Scientific Affairs, LLC, Horsham, PA, USA. The authors report no other conflicts of interest in this work.

\section{References}

1. Gibofsky A. Overview of epidemiology, pathophysiology, and diagnosis of rheumatoid arthritis. Am J Manag Care. 2012;18(13 Suppl):S295-S302.

2. Ollendorf DA, Chapman R, Pearson SD. Targeted immune modulators for rheumatoid arthritis: effectiveness \& value. Institute for Clinical and Economic Review. 2017. https://icer-review.org/wp-content/ uploads/2016/08/NECEPAC_RA_Draft_Report_012017.pdf. Accessed November 30, 2018.

3. Gibofsky A. Epidemiology, pathophysiology, and diagnosis of rheumatoid arthritis: a synopsis. Am J Manag Care. 2014;20(7 Suppl):S128-S135.

4. Birnbaum H, Pike C, Kaufman R, Marynchenko M, Kidolezi Y, Cifaldi M. Societal cost of rheumatoid arthritis patients in the US. Curr Med Res Opin. 2010;26(1):77-90.

5. Singh JA, Saag KG, Bridges SL, et al. 2015 American College of Rheumatology guideline for the treatment of rheumatoid arthritis. Arthritis Rheumatol. 2016;68(1):1-26.
6. Smolen JS, Breedveld FC, Burmester GR, et al. Treating rheumatoid arthritis to target: 2014 update of the recommendations of an international task force. Ann Rheum Dis. 2016;75(1):3-15.

7. Smolen JS, Landewé R, Bijlsma J, et al. EULAR recommendations for the management of rheumatoid arthritis with synthetic and biological disease-modifying antirheumatic drugs: 2016 update. Ann Rheum Dis. 2017;76(6):960-977.

8. Owens GM. Optimizing rheumatoid arthritis therapy: using objective measures of disease activity to guide treatment. Am Health Drug Benefits. 2015;8(7):354-360.

9. Singh JA, Saag KG, Bridges SL, et al. 2015 American college of rheumatology guideline for the treatment of rheumatoid arthritis. Arthritis Rheumatol. 2016;68(1):1-26.

10. SIMPONI ARIA® (golimumab) injection. Prescribing Information. Horsham, PA 19044, USA: Janssen Biotech, Inc.; Revised May 2018. Available from: http://www.janssenlabels.com/package-insert/productmonograph/prescribing-information/SIMPONI+ARIA-pi.pdf. Accessed June 20, 2018

11. Weinblatt ME, Bingham CO, Mendelsohn AM, et al. Intravenous golimumab is effective in patients with active rheumatoid arthritis despite methotrexate therapy with responses as early as week 2 : results of the phase 3, randomised, multicentre, double-blind, placebo-controlled GO-FURTHER trial. Ann Rheum Dis. 2013;72(3):381-389.

12. REMICADE® (infliximab). Prescribing Information. Horsham, PA 19044, USA: Janssen Biotech, Inc.; Revised June 2018. Available from: http://www.janssenlabels.com/package-insert/product-monograph/prescribing-information/REMICADE-pi.pdf. Accessed June 20, 2018.

13. Brady BL, Tkacz JP, Lofland J, Meyer R, Bolge SC. Prescribing patterns of intravenous golimumab for rheumatoid Arthritis. Clin Ther. 2015;37(9):2028-2036.

14. Ellis L, Reed G, Shan Y. Patient characteristics and real-world utilization of intravenous golimumab in a population of rheumatoid arthritis patients observed in the corrona Registry. Academy of Managed Care Pharmacy Nexus 2016. National Harbor, Maryland. October 3-6, 2016. JMCP. 2016;22:S83. Available from: https://www.jmcp.org/pb-assets/ Poster\%20Abstract\%20Supplements/Oct2016Abstracts.pdf. Accessed July 11, 2018.

15. Ting G, Schneeweiss S, Scranton R, et al. Development of a health care utilisation data-based index for rheumatoid arthritis severity: a preliminary study. Arthritis Res Ther. 2008;10(4):R95.

16. Deyo RA, Cherkin DC, Ciol MA. Adapting a clinical comorbidity index for use with ICD-9-CM administrative databases. $J$ Clin Epidemiol. 1992;45(6):613-619.

17. Farley JF, Harley CR, Devine JW. A comparison of comorbidity measurements to predict healthcare expenditures. Am J Manag Care. 2006;12(2):110-117.

18. United States Department of Labor, Bureau of Labor Statistics. "Consumer Price Index (CPI)". Available from: https://www.bls.gov/cpi/. Accessed July 12, 2017.

19. Institute of Medicine (US) Committee on Quality of Healthcare in America. Crossing the Quality Chasm: A New Health System for the 21st Century. Washington, DC: National Academies Press; 2001.

20. The six domains of health care quality (Content last reviewed March 2016). Rockville, MD: Agency for Healthcare Research and Quality. Available from: http://www.ahrq.gov/professionals/quality-patientsafety/talkingquality/create/sixdomains.html. Accessed July 11, 2018.

21. AWARE clinical trial. U.S. National Library of Medicine. 2018. https:// clinicaltrials.gov/ct2/show/NCT02728934.

22. Daniel SR, Mcdermott JD, Le C, Pierce CA, Ziskind MA, Ellis LA. A real-world, multi-site, observational study of infusion time and treatment satisfaction with rheumatoid arthritis patients treated with intravenous golimumab or infliximab. J Med Econ. 2018;21(7):724-731. 


\section{Publish your work in this journal}

ClinicoEconomics and Outcomes Research is an international, peerreviewed open-access journal focusing on health technology assessment, pharmacoeconomics and outcomes research in the areas of diagnosis, medical devices, and clinical, surgical and pharmacological intervention. The economic impact of health policy and health systems organization also constitute important areas of coverage. The manuscript management system is completely online and includes a very quick and fair peer-review system, which is all easy to use. Visit http://www.dovepress.com/testimonials.php to read real quotes from published authors.

Submit your manuscript here: https://www.dovepress.com/clinicoeconomics-and-outcomes-research-journal 